\title{
Exotismo, afán de aventuras e hispanoamericanismo: La ruta de Hernán Cortés, de José Segarra y Joaquín Juliá, entre la hazaña personal y la propaganda oficial*
}

\author{
Almudena Delgado Larios
}

Université Stendhal-Grenoble 3. Francia

En el presente trabajo se analiza el relato de dos periodistas valencianos, José Segarra y Joaquín Juliá, que volvieron a hacer la ruta seguida por Hernán Cortés durante la conquista de México. El viaje y el diario del mismo cuentan con el apoyo de las autoridades mexicanas y españolas puesto que se considera esta hazaña un homenaje de la colonia española y de España a México con motivo de la celebración del Centenario de la Independencia. El estudio se articula siguiendo tres niveles: el de la hazaña personal al ser una ruta accidentada y al poner a prueba la resistencia física de los viajeros; el de la propaganda oficial porfiriana al describir los periodistas los adelantos económicos experimentados por México durante el gobierno de Don Porfirio; y el del mito y visión propagandística del pasado conquistador y colonial —el nivel más interesante, evidentementepuesto que se aboga por una reconciliación entre españoles y mexicanos y se define la mexicanidad como mestizaje.

La ruta de Hernán Cortés... Resulta significativo que dos periodistas valencianos ${ }^{1}$ de principios del siglo XX elijan precisamente este título y, lo que es más importante, decidan repetir la hazaña del extremeño, recorriendo de nuevo, a caballo y en tren, los parajes por los que pasó el conquistador en su ascensión hacia el centro del poder azteca, la gran ciudad de México-Tenochtitlan. En efecto, hablar de México y de Cortés genera inmediatamente polémica. Es un tema que se encuentra íntimamente ligado al de la definición de la identidad mexicana, de la formación de la

* Este es el texto completo de la ponencia presentada en el coloquio Histoire, espace et imaginaire, organizado por el grupo CREATHIS de la Universidad de Lille 3, celebrado en Lille el 21-22 de octubre de 1994. Una versión reducida de diez páginas aparecerá en las actas de dicho coloquio.

1 Un despacho del representante diplomático español en México, Bernardo Cólogan, permite conocer el nombre completo de los dos periodistas, José Segarra y Joaquín Juliá, así como saber que llevaban recorriendo México y otras regiones americanas (Cuba y Centroamérica) antes de emprender la aventura de la Ruta de Hernán Cortés. Tenían asimismo contactos con los dirigentes políticos mexicanos, incluido el mismo presidente Díaz; Archivo del Ministerio de Asuntos Exteriores (en adelante, AAEE), "México", Leg. 2557, n. 41, Política, 12 de mayo de 1910. 
nacionalidad y, en este sentido, se puede decir que la actitud adoptada frente a Cortés delimita las diferentes visiones del pasado mexicano. Por ello, al revalorizar la figura del conquistador, la iniciativa de los dos periodistas adquiere una dimensión cultural e ideológica muy clara. Y así lo vio el representante diplomático español, Bernardo Cólogan, al afirmar que

"la idea, íntimamente ligada a la celebración del Centenario de la Independencia, tenía para nosotros una gran oportunidad patriótica, por cuanto el nombre de Cortés está todavía aquí en entredicho, como consecuencia de rencores, pasiones, exageraciones y prejuicios, incorporados a la historia local y a la enseñanza".

Confía el diplomático español en la labor del tiempo, favorecida por el ambiente de cordiales relaciones existente entre las dos naciones, para ir disipando esa negativa valoración de Cortés. El viaje implica, pues, una redefinición del papel de España en América y de sus relaciones con sus antiguas posesiones tras consumarse la independencia. En este sentido, y como se encarga de resaltar el diplomático español, la fecha de publicación del relato es altamente simbólica: 1910, año de la celebración del Centenario del Grito de Dolores que inició el movimiento independentista mexicano.

Si la simple lectura del título genera estas conclusiones, las dedicatorias del mismo las confirman definitivamente. En efecto, esta obra constituye un acto de afirmación nacionalista-hispanoamericanista desde un punto de vista mexicano y español, y se presenta como el homenaje literario de la colonia española a México con ocasión de la celebración del Centenario de la Independencia. ${ }^{2}$ En la portada, junto a las dos fechas simbólicas de 1519 y 1910, aparece el lema "Pro Patria" en forma de sol ascendente y, en la página siguiente, los escudos de las dos naciones. Además, por si no hubiera quedado suficientemente claro, se especifica a continuación que existe una tirada especial de cien ejemplares que han sido ofrecidos a los reyes de España, Alfonso XIII y Victoria Eugenia, y al presidente de la República mexicana, general Porfirio Díaz, y a su esposa, Carmen Romero Rubio de Díaz, así como a los ministros de ambos gabinetes, a entidades

2 Sin embargo, en sus orígenes, el proyecto fue presentado como una iniciativa exclusivamente individual de los dos valencianos, insistiendo en su condición de "bohemios ambulantes de la españolería". Cólogan afirma que "difícil, por no decir imposible, e inadecuado hubiera sido que, aún en la esfera privada, una colectividad o elemento español en algún modo autorizado tomase alguna a nombre y en homenaje de Hernán Cortés, corriendo el riesgo de provocar susceptibilidades y fracasar, y a la verdad no se intentó". Ibídem. 
científico-literarias, políticas y sociales, y a distinguidas personalidades mexicanas y españolas. Se trata, pues, de una empresa apoyada y fomentada por el poder, con una intención propagandística evidente en los dos países. ${ }^{3}$ Otros elementos confirmarán, como se verá más adelante, el carácter propagandístico de este relato, en múltiples aspectos.

Continuando con la simple observación, la presentación formal apoya igualmente esta primera deducción. La obra está dividida en tres partes y la primera tiene por objeto la explicación de los orígenes de la empresa redescubridora-conquistadora, partiendo explícitamente de una reflexión histórica. Las otras dos partes, muy equilibradas pues constan ambas de seis capítulos cada una, contienen el relato pormenorizado del viaje desde la isla de Cozumel hasta la capital mexicana. Es el relato de un viaje, a través de un espacio concreto, México, y en un tiempo también concreto, el mes que transcurre desde que el barco atraca en Cozumel y los dos periodistas llegan a la capital (13 de abril-13 de mayo de 1910). De entrada, pues, el viaje tiene una dimensión histórica.

Pero, además, la deliberada adopción de un esquema y de un lenguaje arcaizantes, calcados de la crónica de Bernal Díaz del Castillo, revela una determinada concepción de la Historia, junto con el deseo de darle mayor verosimilitud al relato. ${ }^{4}$ En efecto, los dos periodistas adoptan la crónica de Bernal Díaz como modelo y guía para su periplo por tierras mexicanas y por el pasado. Tras esta actitud subyace la convicción positivista de la objetividad del documento histórico, aunque los mismos autores hagan referencia, por boca de Bernal o de otro testigo de la Conquista - el piloto Antón de Alaminos-, a la existencia de versiones distintas y, en consecuencia, a la imposibilidad de establecer los hechos "reales". Pero ese mismo reconocimiento de las dificultades de conocer lo que pasó confirma la adopción del credo positivista puesto que se anima a los estudiosos a proseguir sus investigaciones para llegar a la "verdad".

3 En el mismo informe del ministro plenipotenciario español, se transcribe la carta que Porfirio Díaz entregó a los dos periodistas para que se la dieran al ministro de Estado español. En ella se pide al ministro español que apoye a los dos periodistas que regresan a Madrid para redactar el libro sobre el viaje y que los recomiende al rey.

4 Por otra parte, la adopción del texto de Bernal permite suponer que los autores se habían informado previamente y estaban al corriente de las novedades historiográficas que se habían producido en relación con esta crónica. En efecto, en 1904, el mexicano Genaro García había publicado una nueva versión de la crónica de Bernal, basada en el manuscrito conservado en Guatemala y que recogía los cambios introducidos por el hijo de Bernal. Si esta suposición fuera cierta, habría ya un primer homenaje a México en el terreno cultural. 
Por otra parte, cada capítulo se encuentra precedido, a modo de anuncio y de meditación, por un epígrafe con una cita de una relevante personalidad literaria mexicana y cada cita sirve de hilo conductor del relato, anunciando en síntesis lo que se va a desarrollar en cada capítulo. Este homenaje a través de las citas revela un conocimiento de las tendencias literarias del México porfiriano y de los grupos, asociaciones o sociedades literarias. Por su composición, se aprecia un deseo de conciliar las distintas tendencias y de incluir, dentro de lo posible, a las principales figuras del momento o del pasado inmediato, insistiendo en el carácter mexicano de la producción literaria, una cuestión candente desde mediados de la centuria anterior. ${ }^{5}$ En efecto, a lo largo del siglo XIX, el enfrentamiento ideológico y generacional que opuso a liberales y conservadores impregnó todos los ámbitos de la vida mexicana, llegándose a hablar en el terreno literario de escritores iturbidistas o juaristas. Durante el Porfiriato se calmaron los ánimos en lo concerniente a la política pero, a partir de 1889, estalla la polémica en torno al modernismo. Este relato incluye citas de famosos escritores liberales de distintas tendencias literarias, desde grandes figuras como Guillermo Prieto, Ignacio M. Altamirano (el defensor e impulsor de un grito de Dolores cultural, es decir, de una cultura, de una literatura mexicanas) y Justo Sierra (una de las figuras más importantes del positivismo mexicano), hasta poetas modernistas como Salvador Díaz Mirón, Luis G. Urbina y Amado Nervo, entre otros. ${ }^{6}$

Y el apoyo gráfico desempeña similar función. En efecto, a lo largo de toda la obra se insertan dibujos de los distintos lugares visitados. Y la contemplación de estos dibujos da una nueva pista sobre la intencionalidad de este acto de propaganda, a la vez que demuestran como todo gira

5 Martínez, José Luis: “México en busca de su expresión”, en Cosío Villegas, Daniel (coord.): Historia general de México, vol. 3, México, 1976, págs. 285-331. La cita de Nezahualcóyotl, además de rendir homenaje al rey-poeta prehispánico, hace referencia a la sociedad literaria del mismo nombre, creada hacia 1868-1874.

6 La lista completa de los autores de esas citas, por orden de aparición en los distintos capítulos, es la siguiente: Nezahualcóyotl, Guillermo Prieto (poeta romántico hacia 1836 y gran figura de las letras mexicanas hasta finales de siglo), Francisco M. de Olaguibel (escritor que despunta hacia 1897), Rafael Nájera, Salvador Díaz Mirón (perteneciente a la generación de jóvenes de 1887-1888 adictos al modernismo, a la poesía simbolista y parnasiana), lgnacio M. Altamirano (el gran maestro desde 1834 hasta 1893), Juan de Dios Peza (poeta, de la generación de mediados de siglo, 1867-1889), José Peón y Contreras (también de la generación de 1869-1876), Federico Escobedo, Luis G. Urbina (modernista), Manuel Múzquiz Blanco, G. Fernández de Lara, Francisco A. de Icaza, Amado Nervo (gran figura del modernismo), Manuel J. Othón (modernista) y Justo Sierra (educador, ensayista y gran figura del positivismo). 
en torno al espacio, físico y concreto por una parte, mítico por otra. En efecto, quedan reflejadas las poblaciones visitadas en el estado en que se encontraban en 1910. Por tanto, más que rememorar la Conquista, con sus secuelas de destrucción, violencia y muerte, se trata de revivir la epopeya descubridora/exploradora que constituyó el largo y penoso viaje desde la costa hasta el altiplano, para dar cuenta de la situación del México porfiriano, de los adelantos acaecidos desde los tiempos de Hernán Cortés. Se trata igualmente de unir lo que se había separado, de conciliar, de hermanar a dos pueblos, y de hacerlo en un lugar concreto, simbólico: la cima del Popocatépetl.

Se perfilan así, casi de forma espontánea, las principales líneas de este análisis. En primer lugar, la aventura personal de los dos periodistas, sus sensaciones, sus reacciones ante un paisaje y unas costumbres diferentes a las suyas, las peripecias y las anécdotas del viaje, todo lo cual constituye en cierto sentido una iniciación, el paso a un estado espiritual nuevo. A continuación, el contenido propagandístico de la empresa, directamente ligado a la coyuntura inmediata del Centenario y del gobierno de Porfirio Díaz: qué aspectos del México porfiriano se destacan, qué juicios de valor merecen los distintos grupos sociales, la economía, las costumbres, etc. Y por último, la reflexión en torno al sentido de la Conquista, a la esencia de lo mexicano y a las relaciones profundas que existen entre España y México; en suma, qué filosofía de la historia subyace en este relato y cuáles son sus implicaciones intelectuales y políticas inmediatas. Aquí cobran todo su sentido y relevancia las apariciones fantasmagóricas de los héroes de la Conquista y de la Independencia de México, los cuales establecerán el nexo de unión entre el pasado y el presente. De esta forma, el Porfiriato aparecerá como la feliz culminación de un largo proceso desde lo primitivo hasta la civilización y el desarrollo. Esta idea fue enunciada explícitamente por el representante diplomático español, al afirmar que

"aun siendo grande el cariño por lo indígena, cada día habrá de proclamarse con menos embarazo o escrúpulo que la fundación de la nacionalidad mexicana, orientada hacia la civilización y el progreso, data de la conquista, cuya personificación está en el gran Hernán Cortés, si bien asimilándose el elemento indígena, que fue España la primera, para gloria de nuestra acción humanitaria, en querer proteger y aliarse a él". ${ }^{7}$

7 AAEE, "México", Leg. 2557, n. ํ 41, Política, 12 de mayo de 1910. 


\section{Una ruta iniciática}

Independientemente del contexto político y de su carácter propagandístico, este viaje es, ante todo, una aventura personal de dos hombres jóvenes, sedientos de novedades, de exotismo, de sorpresas y de conocimiento. Lo más destacado de este periplo lo constituye el pasaje desde la inmensidad del océano hasta la montaña - concretamente la ascensión a la cima del volcán Popocatépetl-, antes de llegar a la capital de la nación. Son dos episodios decisivos para el desarrollo de la acción, tanto desde el punto de vista personal como intelectual y propagandístico.

No es casual, por tanto, que la cita que ilustra el primer capítulo se refiera al devenir del ser humano a partir de la ya clásica referencia a los ríos, arroyos y fuentes como símbolo del curso de la vida humana. ${ }^{8}$ Desde el principio, por la forma de introducir el viaje, se indica que se trata de un viaje iniciático. Lo confirma la presencia de los elementos más característicos y simbólicos relacionados con la aventura del conocimiento. En efecto, la primera imagen es la de dos hombres pensativos en la cubierta de un barco que surca el inmenso océano. Por consiguiente, los dos héroes se encuentran en uno de los cuatro elementos fundamentales, el agua, y navegan en una blanca nave, de noche, a la luz de la luna. ${ }^{9} \mathrm{He}$ aquí todos los elementos de un rito de iniciación, de transición hacia un nuevo estado, el cual implica conocimiento, sabiduría. En este sentido, todos los elementos se refuerzan y se complementan simbólicamente. El agua está tradicionalmente asociada a la sensibilidad, a la emotividad; la luna simboliza el conocimiento teórico, indirecto, y también la imaginación, el sueño, un cierto estado de receptividad del ser que impulsa a la aventura. Por otra parte, para referirse al peligro que supone la vida, el barco encarna la seguridad pero también el principio y el fin, la vida y la muerte por su color blanco, la transición, el pasaje de un estado a otro. Esta imagen se ve reforzada por la presencia del mar, reino de la duda, de lo incierto.

8 La estrofa es de Nezahualcóyotl, rey-poeta cuyos poemas fueron traducidos a finales del siglo XVI y principios del XVII por un descendiente mestizo, hijo de conquistador y de india, Fernando Alva Ixtlixóchitl. Se pretende rendir homenaje al pasado azteca de México y a la cultura nacional puesto que su figura fue reivindicada en el siglo XIX como elemento importante, junto con el legado hispánico, de la nacionalidad mexicana.

9 Aunque las referencias aparezcan en el primer capítulo, en el primer párrafo, la descripción del decorado que ambienta y fomenta las reflexiones históricas de los protagonistas aparece en el capítulo tercero, en las páginas 40 a 48. 
Que se trata de una ruta hacia el conocimiento lo avala la larga disgresión del primer capítulo sobre la Historia y la necesidad de luchar contra la ignorancia, las falsedades, los tópicos, para alcanzar la paz en su conciencia. A este respecto, el narrador afirma que "el mísero mortal - juego del tiempo, la ocasión y el caso- acaba por entrar en los dominios de la razón en calma, viendo hoy luz y esplendores donde acaso vio ayer negrura densa" ${ }^{10}$ Casi se podría encontrar una comunidad de lenguaje con los ritos masónicos, puesto que los dos hombres parten del Agua, del reino de la sensibilidad y de la emotividad, y se dirigen hacia el Aire - en la cima del volcán-, hacia lo intelectual y filosófico, sin desdeñar la Tierra, la vida material. Y que parten del sentimiento, lo destacan ellos mismos: "Amor y Sentimiento no han menester copiosa erudición, ni crítica sutil, ni hábil dialéctica ingeniosa. Que ellos tan sólo - Sentimiento y Amor- son las banderas que haremos ondear al meridiano sol y al viento puro de las cumbres altísimas, sobre el florido campo do Méjico y España van a hermanar sus glorias y grandezas - siempre hermanas...". Las referencias a los mitos clásicos, a los dioses y héroes del pasado más remoto, plasman perfectamente esta idea de recorrido intelectual, a la vez que constituyen un recurso retórico — que apelmaza sobremanera el estilo - para describir pseudopoéticamente el paisaje circundante. Así, la luna es "argéntea, sutilísima hoz dejada por Apolo entre la flora centelleante de los vergeles siderales", el mar, momentáneamente tranquilo, tiene "pacto de enojos y acechanzas con Aquilón el pérfido, pontífice de Eolo en las regiones del Caribe". ${ }^{11}$

Y en la soledad, las tinieblas y el silencio, los dos protagonistas ansían recibir una señal que les guíe en su empresa - de nuevo un artificio clásico. Y la señal llega, evidentemente, con el alba. De nuevo la imagen de la luz blanca, la luz primigenia, y del aire que eleva la mente. Así describen la aparición de la Voz que responde a la advocación de los dos españoles y que pertenece a uno de los héroes de la Independencia de México: Morelos (coincidiendo con el nombre del barco que los conduce hacia la costa y hacia la sabiduría). El discurso del fantasma de Morelos refleja ya, como se verá más adelante, la concepción de la historia de México como recorrido hacia el Progreso y como conjunto rico y armonioso de elementos aztecas e hispánicos. Y tras la revelación, tras la chispa que ilumina y ensancha la mente del hombre, llega el reino de la luz, pero de la luz solar, símbolo por excelencia del conocimiento.

10 Segarra, J.; Juliá, J.: La ruta de Henán Cortés, Madrid, 1910, pág. 18.

11 Ibídem, págs. 40-41. 
Tras estas referencias simbólicas, en el capítulo quinto, el narrador explicita claramente el carácter de aprendizaje, de paso de la ignorancia a la sabiduría, que reviste este viaje. Tratando de seguir la ruta de Cortés, no se pretende - se señala en el texto- hacer labor de ratificación o de rectificación histórica, ${ }^{12}$ ya que semejante tarea compete a los hombres doctos, a los hombres de ciencia y, por el contrario, los dos aventureros son dos humildes aprendices de todo y maestros en nada. Y aquí se hermanan el propósito individual y el político-propagandístico puesto que se afirma que la Ruta es

"el pretexto a fin que nuestras almas — como almas españolas - al alma mejicana brinden un abrazo de hermanos, haciendo que se abracen en fecha memorable sombras augustas de dos gloriosas razas, cuya fusión determinó una raza hoy viril y pujante, un pueblo heroico, una patria ilustre". ${ }^{13}$

El otro episodio digno de mención desde el punto de vista de la aventura personal es el ascenso a la cima del volcán Popocatépetl. Constituye, además, el único momento de peligro real, de presencia de lo desconocido, de enfrentamiento del ser humano con las fuerzas de la naturaleza. En efecto, en los capítulos anteriores, se describe el paisaje y las localidades visitadas pero el interés se centra en la descripción de los campos, la industria, el progreso técnico, y no en los efectos de ese medio físico nuevo sobre los dos personajes centrales. El relato de la ascensión ocupa los capítulos trece, catorce y quince, pertenecientes a la tercera parte de la obra. Existe un paralelismo formal con el primer episodio, la aparición fantasmagórica de Morelos en el mar, puesto que éste ocupa también tres capítulos de la primera parte. Se trata, por tanto, de los dos episodios más importantes, desde todos los puntos de vista.

Los dos personajes y su comitiva inician el ascenso entre el frío, las sombras de la noche, ruidos extraños y animales misteriosos y amenazadores por desconocidos.

"El viaje toma el carácter de una temeraria aventura. Por si la noche sin luna y sin estrellas, no fuera asaz oscura, el camino es un túnel abierto en la arboleda espesísima, entre altas paredes y se hace peor a cada instante, internándose en una angosta garganta de la sierra donde no son escasos los obstáculos. La noche negra, la selva impenetrable, el sendero llevándonos al fondo pedregoso de la angosta barranca....". ${ }^{14}$

12 En efecto, sigue sin haberse establecido la ruta seguida por Cortés en su ascenso hacia Tenochtitlan ya que las distintas crónicas dan datos diferentes y a veces contradictorios.

13 Segarra, J.; Juliá, J.: La ruta..., pág. 67.

14 Ibídem, págs. 191-192. 
Todo indica que se trata de la prueba decisiva, que determinará el éxito o el fracaso de la aventura, física e intelectual, de los dos periodistas. Referencias al infierno, al abismo, a los cuentos de terror, al alma atormentada de los fantasmas de los antepasados que perecieron en el intento, elementos todos que apuntan hacia el rito de pasaje. La referencia más clara es la del túnel, real y simbólico, es decir, el camino angustioso, que se recorre sumido en el terror ante las dificultades de la empresa a realizar, pero también el camino hacia la luz, hacia el conocimiento.

El túnel se complementa con la imagen de la montaña, doblemente significativa en este caso ya que, por tradición clásica del mundo occidental y por tradición azteca del mundo prehispánico americano, se trata de una montaña sagrada. Constituye el punto de contacto entre el cielo y la tierra, entre el mundo de los hombres y el mundo de los dioses (en este caso de los héroes del pasado). Refleja igualmente el destino del hombre, en el sentido de elevarse del abismo de la ignorancia hacia las alturas, hacia la sabiduría. El hecho de que la ascensión se realice de noche refuerza la idea de paso del caos, de la oscuridad de los orígenes, hacia la luz de la creación y del saber. De esta forma, se prepara el camino para la revelación de carácter filosófico-histórico-político que constituye el eje conductor de este relato, es decir, la aparición en la cima del volcán de los dos héroes fundadores de la nación mexicana (Cortés y Cuauhtémoc) y el cortejo de personalidades de ese pasado común, desde la Conquista hasta la Independencia. Además, la presencia de animales extraños, negros por la falta de luz, apunta hacia la superación del componente primitivo del hombre, y por extensión de las sociedades humanas, alcanzando el estadio de civilidad, de progreso. Se confirma, así, la total coherencia existente entre los tres elementos conductores del relato, el individual, el socio-político y el filosófico.

A medida que ascienden, se intensifica la sensación de prodigio, de creación, de estallido, de aparición de algo sobrehumano. "Negros nubarrones, en fantásticos remolinos, vienen de lo más alto de la sierra, como humareda de cien volcanes", y pronto cae una furiosa granizada. A las inclemencias del tiempo se añade el hambre y el cansancio, la falta de refugios donde guarecerse. "El espectáculo es dantesco, los pinos de troncos retorcidos, gesticulan abofeteados por la furia del vendaval". ${ }^{15}$ Es el preludio de la revelación final, pero también la prueba del carácter indómito de

15 Ibídem, pág. 198. 
la naturaleza, de los desafíos constantes que le lanza al hombre. Por otra parte, la imagen de la tormenta, del granizo y de los truenos constituye una prueba más del deseo de aunar tradiciones y culturas, la hispánica y la prehispánica. En efecto, se trata de un símbolo común a todas las culturas. La lluvia fertiliza, es el símbolo de la vida, de la fecundación. Y, en este caso, en la montaña mágica de los aztecas truena Tláloc, dios de la lluvia y del rayo. Y en la cultura occidental, junto con el significado agrario, se asocia también a un mensaje divino. De esta forma, se anuncia el acontecimiento insólito que va a producirse.

El paso del cometa Halley, además de ser un hecho real acaecido en 1910, sirve para realzar el carácter excepcional y privilegiado del viaje y le otorga su dimensión mítica, equiparándolo al viaje real de Cortés, pues según Bernal Díaz, hubo señales y planetas en el cielo de Nueva España antes de que se produjera la llegada de los españoles. Viene a ser la demostración de que el eje conductor del viaje (demostrar el progreso de la "raza mexicana" y reinterpretar el pasado, asumiendo y ensalzando la unión de dos culturas, el mestizaje) no es fruto de la subjetividad de los protagonistas, no responde a ningún planteamiento particularista, sino que está inscrito en el orden lógico de las cosas y que era cuestión de tiempo, de madurez política e intelectual, descubrirlo. La coincidencia del paso del cometa con los dos momentos elegidos —el pasado de la auténtica Conquista y el presente de la rememoración - constituiría un argumento más para justificar la empresa, que sería el fruto del destino, de la ley inexorable de la Historia. La contemplación del cometa tiene, evidentemente, importancia también desde el punto de vista estrictamente individual, personal, puesto que es un prodigio que sólo puede verse una vez a lo largo de una vida.

Por otra parte, la ascensión a la cima del volcán, episodio que se repite en otros relatos de viajeros europeos por el México decimonónico, supone una hazaña de los tiempos modernos, frente a las supersticiones antiguas. Encarna el triunfo de la ciencia, del conocimiento racional, base del progreso y de la civilización. Y, en el caso mexicano, ambos vinieron de la mano de los conquistadores españoles. "Inevitablemente acude al pensamiento el recuerdo del atrevido Diego de Ordaz y sus acompañantes, desafiando los primeros la miedosa tradición indígena que aseguraba la muerte a quien intentase penetrar el misterio de la montaña humeante". ${ }^{16}$

16 Ibídem, pág. 199. 
El tramo final lo suben los protagonistas a pie, casi a rastras, arañando el suelo con las manos. Y el esfuerzo, la altura, el frío, la falta de aire producen una sensación de angustia y de asfixia. Al llegar al cráter, se unen el estruendo del volcán y el amanecer para alumbrar la aparición del cortejo de héroes y sellar la reconciliación final entre los dos pueblos. Los dos viajeros reciben así la recompensa por su esfuerzo y por su voluntad de saber, de perfeccionarse, de conocer.

\begin{abstract}
"Con el beso de la luz diurna, las nubes se estremecen, diríais que gozosas, y forman remolinos fantásticos; y la luz, absorbida por la intensa blancura del cono del volcán, hácenos ver desde el borde del cráter reflejados en el bruñido apisonado de aquel jaspe de hielo, cuantos caprichos engendran las masas de vapor en su oleaje, y que toman vida en nuestra mente y retina debido a la potencia creadora de la fantasía ebria de la grandiosidad de aquel momento. ${ }^{17}$
\end{abstract}

El espíritu positivista impide presentar el prodigio como algo real pero, a pesar de salvar las apariencias aclarando que es el fruto de la imaginación, no deja de ser significativo que se recurra a la imagen ya tradicional del cortejo de héroes apareciendo en el cielo y dirigiéndose a los hombres para guiarlos por el buen camino. De nuevo, para referirse a ese momento en que se consuma el pasaje del estado de ignorancia al de sabiduría, se recurre a la metáfora de la luz blanca, del sol ascendiendo, del día que despunta.

En conclusión, desde el punto de vista personal e individual, casi íntimo, el espacio mexicano aparece revestido con todos los atributos de un paraíso exótico, que pone a prueba las facultades y la resistencia física de los hombres (el calor, las largas distancias, los vientos, las tormentas, las escaladas). El éxito de la empresa constituye toda una hazaña personal de los dos periodistas, que han demostrado así su fortaleza física y mental para afrontar los retos de un espacio extraño en todos los sentidos. Y este espacio es histórico y ahistórico a la vez. Por una parte, las gentes y, sobre todo, las técnicas han progresado. Pero, por otra parte, la presencia de la naturaleza en toda su fuerza y esplendor - sigue siendo un espacio sin humanizar por completo, por tanto, salvaje y retador ${ }^{-18}$ genera las mismas reacciones interiores en los hombres del siglo XX que en los del siglo XVI

17 Ibídem, pág. 217.

18 A este respecto es significativo que no aparezcan referencias a las ciudades y, especialmente, a la capital de la nación. El espacio urbano, símbolo de desarrollo y modernidad, está totalmente ausente. 
(ritos de "pasaje" hacia un conocimiento más profundo y hacia una conexión con la divinidad o con los héroes). Además, este viaje — con aires de aventura iniciática - sirve, desde el punto de vista individual como excusa para que sus protagonistas realicen una incursión en el mundo literario, dándose aires de escritores modernistas.

\section{El Porfiriato: Orden y Progreso}

Si al contemplar el índice de la obra, se podía pensar que los dos periodistas iban a volver a contar la aventura de Cortés puesto que recurrían a la grafía y al estilo de los cronistas, insertando una frase-resumen a modo de título de cada capítulo, la lectura del relato revela que el propósito es muy diferente. Se trata de exaltar el progreso material de México y de identificarlo con un personaje concreto, Porfirio Díaz. Es bien conocida la preocupación de este presidente eternamente reelegido de poner fin al tópico imperante en el mundo civilizado de un México anárquico, salvaje, primitivo, víctima del banditismo, imperio de la violencia. Su proyecto de consolidar el Estado-nación implicaba control del territorio y explotación de los recursos naturales, para lo cual era absolutamente necesario atraer el capital y la tecnología extranjeros. Para formar una ciudadanía responsable se pensó igualmente en propiciar la inmigración europea, a imagen y semejanza de Estados Unidos, y diluir así, e incluso suprimir y exterminar cuando se trataba de tribus nómadas, el componente indígena. Había que consolidar una nación mestiza, cuanto más blanca y occidentalizada mejor.

Los relatos de los viajeros europeos cobraban, pues, una importancia decisiva puesto que, con la prensa y los informes de los representantes diplomáticos, configuraban la imagen dominante del país en el exterior. Apadrinando la aventura de los dos periodistas españoles, el gobierno porfiriano conseguía difundir sus logros y controlar las opiniones vertidas en el relato para evitar que se infiltraran críticas o aspectos negativos de la realidad mexicana. Esa participación oficial revistió varias formas. En primer lugar, la militar o policial. Así, el cortejo de los dos periodistas incluye una protección oficial, un grupo de los tristemente célebres Rurales. ${ }^{19}$ En

19 "E digamos como en lantigua fueron a nos. Esperar por mandado y orden del Gobernador que está En Xalapa, unos soldados que se dizen Rurales y había allí también Cavallos para nuestro Serviçio...”. Segarra, J.; Juliá, J.: La ruta..., pág. 110. 
segundo lugar, la presencia política encarnada por las autoridades locales y nacionales (alcaldes, gobernadores, miembros de la oligarquía) que, en varias ocasiones, durante el trayecto de una población a otra, acompañan a los españoles, organizan recepciones y manifestaciones de apoyo con gritos de exaltación a España y a México. ${ }^{20}$ Es revelador el caso de don Cruz de Acosta que acompaña a los dos españoles por Veracruz, personaje

"que tiene trato y grande Amistad con el Ecçellentíssimo General que ahora es Presidente en la gran çibdad de México. Pues quando el suso dicho General que se dize don Porfirio Díaz iba por estas fragorosas soledades y lo perseguían y estaba en desgracia de los que entonces mandaban en el govierno, el dicho don Cruz entonçes le traya los aprovisionamientos de cosas Comestibles y dello se acuerda siempre el jefe. ${ }^{21}$

Se desvelan así los resortes del porfirismo para asegurar la estabilidad. En efecto, don Cruz es un antiguo compañero de fatigas en las luchas por el poder y, en función de esa amistad, consolida su influencia en la región.

En tercer lugar, el poder controla la información y la difusión de las peripecias del viaje a través de la prensa. En el texto aparecen varias referencias $\mathrm{y}$, en el último capítulo, se incluyen fragmentos de los artículos que los principales diarios mexicanos le dedicaron a la aventura de los dos españoles y donde figuran las personalidades que recibieron a los nuevos "conquistadores" españoles.

En consecuencia, la visión que ofrece este relato está condicionada por esa cobertura oficial. Se puede suponer que las poblaciones y los individuos afectados no actuaron espontáneamente y, en especial, no pudieron dar una visión diferente, más real, de la situación del país y de los problemas imperantes. Buena prueba de ello es la alusión al asombro y temor que despierta a su paso la comitiva. "Son curiosos los comentarios que, dichos en voz baja, con aire de misterio, sorprendemos entre los grupos de la gente. Los soldados de la escolta es lo que más preocupado trae al pueblo soberano". Nótese el hecho de referirse al pueblo soberano puesto que, aunque

20 Un ejemplo es el recibimiento entusiasta organizado en Jalapa por un grupo de 500 estudiantes y la posterior recepción de la colonia española y de las personalidades de la localidad: profesores, abogados, comerciantes, obreros, una banda de música; Ibídem, págs. 145-148. Con esta enumeración se pretende demostrar que todas las capas de la sociedad mexicana aprueban y apoyan el proyecto y, al expresar su júbilo ante la llegada de los españoles, manifiestan ese estado de felicidad, bienestar y concordia que caracterizaría a la sociedad porfiriana, libre de fisuras y de tensiones. Resulta paradójico si se piensa en los inmediatos acontecimientos que "revolucionaron" este edificio social aparentemente tan estable y tan sólido.

21 Ibídem, pág. 116. 
desvirtuada en la práctica electoral por el fraude, la República Mexicana tiene la forma de una democracia liberal parlamentaria. También resulta ilustrativa la alusión a los soldados como causa del temor de los habitantes. ¿Piensan tal vez que se trata de una ola de represión? Las conjeturas de la gente - se dice - van desde que se trate de una "tropa alzada" — en evidente alusión al inestable pasado de México, y puede que a su presente-, o "gringos que, con apoyo del Gobierno vamos a tragarnos de un sorbo la sierra entera con todos sus pinares, caseríos, ganados y habitantes" - plasmación del espíritu antiyanqui y de la conciencia que tienen los mexicanos del peligro del Norte..$^{22}$

Refiriéndonos más concretamente al tratamiento del espacio, por imposiciones de la ruta seguida por Cortés, la descripción de las tierras mexicanas arranca en la zona tropical. La lectura de otros relatos de viajeros confirma esta opción, que responde sencillamente a la progresión lógica, en esa época, que conducía al viajero desde la costa donde desembarcaba del barco de vapor hasta la capital de la República, a caballo o en tren. Todos los recién llegados se topaban con las tierras bajas, con su vegetación lujuriosa, con el calor y con los peligros de la fiebre amarilla.

Los dos valencianos se estrenan en la isla de Cozumel, auténtico paraíso, libre de la tan temida enfermedad: el mar, de "un azul tan intenso y transparente que a gran profundidad se ve su fondo, que finge la color pavimentado de lapislázuli", la costa donde se disputan el suelo y el espacio las palmeras, "las yerbas y matas de hojas charoladas con barniz de esmeralda, sarmentosas de flores embriagantes, las cañamiel de lanzas amarillas, el banano de pencas quebradizas y arbustos y lianas, cactus y agaves varios: la rica, incomparable vegetación de esta tierra de ensueño, fecunda hasta el prodigio, fértil hasta el milagro". ${ }^{23}$ El idílico cuadro se completa con un pueblecito de blancas casas, donde reinan la paz, la alegría, la prosperidad (lo confirma la descripción del mercado local, rebosante de productos mexicanos y extranjeros, puesto que Belize está cerca) y el saber, ya que la capital, San Miguel, con ochocientos habitantes sostiene cuatro escuelas. El mensaje es claro y directo: esta selva lujuriosa no es peligrosa, sino todo lo contrario, y este primer atisbo de México anuncia lo que será la gran constante, la riqueza, las infinitas posibilidades de hacer negocio o de poner en explotación tierras y minas. Se intenta, así, atraer emigrantes y capital españoles.

22 Ibídem, págs. 193-194.

23 Ibídem, págs. 68-69. 
Y, además, la presentación de este primer contacto con el trópico adopta prácticamente la forma de un folleto turístico para incitar al viaje, a la huida del excesivamente civilizado paisaje occidental para refugiarse en este pequeño paraíso. Una vez más, América y el paraíso se confunden, formando un mismo espacio donde puede florecer la utopía de un mundo mejor y más próspero. En la exaltación de los españoles al describir esta isla de ensueño se percibe el eco de la atracción por lo primitivo y salvaje, sentido como lo puro y auténtico frente al artificio de la sociedad industrial. Sin embargo, no hay que pensar que se denigra y condena la civilización occidental. En 1910, y a efectos propagandísticos aún más, se exalta sistemáticamente la superioridad del progreso tecnológico, única vía de alcanzar la felicidad.

Tras esta primera impresión, los dos periodistas inician la ruta propiamente dicha, pasando de las tierras bajas a las altas. Se repiten las mismas referencias a la riqueza, a la fertilidad, a la abundancia de plantas y flores, incluyendo un recuerdo de las huertas de Valencia desde esas tierras de Jalapa. Con todo, las alusiones al paisaje son mucho más escasas que al principio, pues el interés se centra en el progreso económico y técnico potenciado por el gobierno de don Porfirio. Es la parte propagandística del relato. Y los aspectos más destacados indicarán los puntos considerados prioritarios tanto por el gobierno como por los extranjeros.

En el centro de las preocupaciones se encuentra el desarrollo comercial, lo cual es lógico puesto que el Porfiriato supuso la plena incorporación de México al comercio internacional como proveedor de materias primas y de productos agrícolas. Pero esta participación de México en el comercio mundial se remonta a la época de la Conquista y posterior colonización por parte de los españoles. Para hacerlo más patente, se recurre al testimonio de uno de los primeros españoles que pisaron tierras mexicanas, el piloto Antón de Alaminos, el cual inicia la enumeración de "los adelantos que ha presençiado esta Mar, y yo en ella, como Testigo de tales e tantas maravillas".

En primer lugar, no puede desarrollarse el comercio en particular, ni la vida civilizada en general, sin paz, sin orden. Desde el siglo XVI hasta la fecha se ha pasado de

"hombres mostrudos en ydolatrías e otras fealdades a gente de muy lindo acatamiento, aisí como son tanto sin engaño y tan liberales de lo que tienen y digo que los dichos pueblos y çibdades se enriqueçen con muy variadas y diversas yndustrias de habilidad e provecho grande y muy notable". ${ }^{24}$

24 Ibídem, pág. 82. 
Prosigue el piloto destacando la riqueza que siguió a la Conquista con el desarrollo de la ganadería, la explotación de las minas, el comercio de especias, la exportación a Europa de plantas nuevas que serán decisivas más adelante, como el algodón, la patata o el maíz, las maderas preciosas, los tintes naturales (en especial la cochinilla), las frutas exóticas como la piña o el plátano, el café y un largo etcétera. En esta enumeración se encuentran los principales productos de exportación de México aun en 1910, con algunas excepciones (como consecuencia de la sustitución de determinados productos naturales, como los tintes, por productos sintéticos).

El destino lógico de todos estos productos maravillosos fue, desde el siglo XVI, Europa. Alaminos enumera los productos y, sobre todo, da cifras relativas al valor de ese comercio, en 1819 y en 1909:

\begin{abstract}
"El comercio total de Entrada y de salida, que se hizo en doscientos y diez y nuebe Buques, fue de diez y ocho millones seteçientos y setenta y ocho Pesos fuertes; y para comparar el progreso e los tiempos, solamente en el Mes de nobiembre del último año pasado o séase el de Mill nueveçientos y nueve años, el movimiento de entradas y salidas por este Puerto [rrefiero aquí tan sólo el Tráfico internaçional, no contando el nombrado de Cabotage] está representado por treynta y seis navíos y cincuenta millones y uno más de quilos de mercaderías, con un valor en Pesos megicanos de ocho millones tresçientos y ochenta y ocho mil y çiento treynta y çinco".
\end{abstract}

Aclara que por Veracruz, si antes salía la totalidad de lo exportado desde México, en esos momentos sólo representa la cuarta parte, puesto que el valor total del comercio exterior asciende a unos trescientos ochenta y siete millones de pesos. ${ }^{25}$ Por tanto, se ha pasado de 18 a 387 millones, confirmando así la idea de un desarrollo espectacular en el siglo XIX, y más concretamente en los últimos treinta años.

Para impulsar el comercio resulta imprescindible desarrollar un sistema de comunicaciones rápido, seguro y eficaz, que conecte, en el tiempo más breve posible, los centros productores a los exportadores. De nuevo aparecen las alabanzas a la gestión de don Porfirio puesto que bajo su gobierno se han construido faros (para una navegación más segura), se han acondicionado los puertos, y se ha abierto el país al Dragón negro, esto es, al ferrocarril. Veracruz simboliza este progreso. En efecto, si desde la época de su fundación por Cortés hasta 1881, "la bahía, por lo desmantelada, era el espanto de la gente de mar" (confirmado por documentos de 1804 y

25 Ibídem, pág. 98. 
1807 relativos a los hundimientos de barcos en el puerto a causa del temido Norte), tras derribarse las murallas, construirse escolleras y ampliarse los muelles, junto con el asfaltado y alcantarillado de las calles, la ciudad se ha convertido en "la puerta de Méjico que mira a Europa y en uno de los mejores timbres de justo orgullo a honra del gobierno central". ${ }^{26}$

Tras Alaminos, le llega el turno al más célebre cronista de la gesta cortesiana, Bernal Díaz del Castillo. Será el encargado de guiar a los dos viajeros hasta la antigua Tenochtitlan. Y, juntos, harán parte del camino en el milagro de la industrialización, el ferrocarril. Explotando a fondo el anacronismo $^{27}$ y para darle mayor verosimilitud a la aparición fantasmal del cronista, se describe como si de un dragón de las historias de caballerías se tratara la aparición del ferrocarril. ${ }^{28}$ Para Bernal es la encarnación del mal, del demonio, y él mismo actúa como un auténtico caballero, dispuesto a desenvainar la espada para destruir al monstruo. Ya en la demoníaca máquina, el cronista descubre el secreto de la tracción a vapor y las ventajas del artefacto que ha permitido vencer las distancias y los obstáculos de la naturaleza, así como generalizar las comodidades y mejorar el nivel de vida de todos los hombres, reduciendo las diferencias entre "grandes" y "pequeños", lo cual implica una cierta abolición de los privilegios. En suma, el ferrocarril es el instrumento del Progreso que eleva al hombre y lo aleja de su condición animal. En el caso mexicano, la elevación es física, real, material, puesto que ese tren acerca al hombre a la cumbre del volcán. Se expone aquí la teoría de la felicidad basada en el progreso científico y

26 Ibídem, págs. 105-106.

27 ¿Quién resiste al deseo de atraer a estos tiempos de adelantos pasmosos a alguien que represente las épocas remotas, estableciendo así el contraste peregrino del alma y de la vida de ambas edades, imaginándose — diremos por ejemplo— resucitar en pleno siglo XX a un hombre que vivió tres, cinco, ocho o doce siglos antes? ¿Quién no ha pensado nunca en los cruzados de Gofredo de Bullón yendo a Jerusalem en automóvil, o en Cervantes escribiendo a máquina el Quijote, o en Nerón en su baño con luz, ventilador y estufa eléctrica, o en Carlos V dictando por telégrafo las órdenes que impone a medio mundo?" Ibídem, pág. 162. Resulta significativo y muy ilustrativo el hecho de que el recorrido se realice a caballo — a imagen de Cortés - y en ferrocarril. Se unen el pasado y el presente, en total armonía. Todos los elementos, por tanto, encajan perfectamente en función del objetivo principal: conciliar el pasado y el presente de México como un todo, un continuo, sin rupturas.

28 Los dos periodistas son fieles al espíritu de la crónica de Bernal Díaz pues, como han señalado numerosos estudiosos, en ella se palpa la influencia de los libros de caballerías. Al respecto ha escrito Manuel Alvar: "El texto (de Bernal) además de hermoso, es ejemplar. Doblemente ejemplar: eran, sí las inauditas maravillas, pero también la explicación del milagro inevitable. Cosas de encantamiento que cuentan en el libro de Amadís. El conquistador iba a hacer vida aquel libro de caballerías que sólo existió en la fábula y la vida se iba a convertir en un paradigma literario"; "Americanismos en la "Historia" de Bemal Díaz del Castillo". Revista Española de Filosofía, Madrid, 1970, anejo LXXXIX, pág. 4. 
técnico, muy en boga a finales del siglo XIX y principios del XX, junto con la idea de que el desarrollo de la industria y del sistema capitalista en general conducirá a la desaparición de los privilegios. Lo cual se revelaba absolutamente falso, evidentemente.

Pero todo el progreso material no serviría de nada si no se hubiera vencido una de las plagas de la evolución política mexicana desde la independencia: la anarquía, el desorden, el banditismo. Así, durante la ascensión a la cima del volcán, se reseña el paso por un lugar, llamado el Mirador,

"de nombre amable pero historia trágica. Desde aquella terraza o balcón natural, se gozan, en efecto, perspectivas soberbias. Pero aquello, en no remotos tiempos, fue la atalaya preferida de los sallteadores que infestaban el país dándole triste fama por la inseguridad de los caminos". ${ }^{29}$

Esta plaga, según los protagonistas, ha desaparecido. De esta forma se disipan los temores de los extranjeros. Así, el espacio mexicano, antaño salvaje y violento, se humaniza progresivamente, se civiliza a medida que el hombre extiende su dominio sobre él, en una línea tanto individual (proeza de llegar hasta la cima) como estatal o colectiva (creación y mantenimiento de unidades militares o policíacas que aseguren el mantenimiento del orden).

La exaltación del sistema porfiriano de gobierno se lleva a cabo a través de un ejemplo concreto, de un gobernador que acompaña a los expedicionarios por tierras tlaxcaltecas. Es campechano, honrado, fomenta las obras públicas y estudia de "manera directa las cosas de su tierra, acerca de las cuales se documenta en la realidad, en sus propias investigaciones, no de oídas y de segunda mano". Toda una definición del método positivista seguido fielmente por los gobernantes mexicanos (conocidos como los Científicos). Gracias a ese celo administrador — pero mucho más a la represión ejercida por los Rurales - los dos jóvenes periodistas no se topan con los antiguos forajidos que sembraban el terror en los caminos de la República.

El colofón de todo este panegírico es evidentemente la ausencia total de elementos negativos, de sombras que puedan empañar la gloria de don Porfirio. Las alusiones a los indios reales son escasas y se limitan a los tópicos de humildad y pereza con algún toque de miedo por lo impre-

29 Segarra, J.; Juliá, J.: La ruta.., pág. 196. 
visible de sus reacciones,$^{30}$ pero todo extremadamente matizado puesto que el objetivo del relato es afirmar la superioridad de la nueva raza mexicana, fruto de la indígena y de la ibérica. Por ello, se huye de los pobladores reales y de su estado de ignorancia, servidumbre y postración puesto que esto implicaría criticar el "progreso" y "desarrollo" porfirianos. El indio es, para estos dos viajeros, casi exclusivamente un ser mítico y, por ello, irreal y casi inexistente puesto que se ha fundido con el ibero, dando lugar a una nueva raza, la mestiza mexicana, superior, objeto de exaltación y artífice de ese desarrollo político, económico, social y cultural que se describe en este relato.

\section{La Nueva Conquista: el abrazo de Cortés y de Cuauhtémoc}

El tercer aspecto analizado, y no el menos importante precisamente, es el intento de redefinición de la historia de México, y también de España evidentemente. Como ya se ha apuntado al principio, sería éste el objetivo primordial del viaje y del intento de reconstrucción de la ruta seguida por el conquistador extremeño. La exposición más teórica de este propósito figura en los cuatro capítulos iniciales que conforman la primera parte del libro. En los capítulos finales - trece a dieciséis - se plasma esa reconciliación entre México y España de dos formas: la mítica y sobrenatural de la aparición celeste de los grandes personajes históricos, y la más terrenal y política del recibimiento de los viajeros en la capital mexicana, con todos los honores, por parte de las autoridades mexicanas y de las personalidades relevantes de la colonia española.

Desde las primeras páginas, se anuncian los objetivos intelectuales del viaje. Y, en primer lugar, se trata de modificar la concepción de la Conquista imperante en España y en México. Se lamentan los periodistas del "castigo, duro y fuerte, (que) es para esas deturpadas crónicas, cuando ellas son escritas en castellana lengua, ver que del honor nuestro y nuestra historia se hacen voceros otras gentes que sienten con otra alma y sirven a otra patria y escriben otras lenguas". ${ }^{31}$ Esta reivindicación de una historia española o hispánica, que ponga fin en cierto sentido a la Leyenda negra,

30 Al describir el asombro y temor de los indígenas ante la comitiva armada, se afirma en un inciso que no son exentos de malicia, ni tan ingenuos e inocentones como piensan muchos; Ibídem, pág. 194.

31 Ibídem, pág. 17. 
es un componente más de la batalla por una cultura nacional, mexicana y española. Y esta aspiración no es el fruto de una opción ideológica, afirman los españoles, sino que se deriva de la Historia, “¡Diosa augusta, que, impávida, serena, inconmovible, asienta sobre bloque diamantino sus juicios eternos!". De entrada,pues, estamos frente a un ejercicio de revisión histórica - por naturaleza, de carácter ideológico- que se ampara en una supuesta imparcialidad. No deja de ser un acto algo pretencioso puesto que los dos viajeros se presentan como simples transmisores del mensaje de la Historia.

La tesis que guía todo el proyecto es la de la hermandad entre España y México,

"dos banderas, dos pueblos, dos historias que son, por sobre mil tristuras y dolores pretéritos, un solo étnico ser, una bandera y una historia, hechos UNO a la sombra del Lábaro bendito que hermanara el plumado penacho al férreo capacete, y por virtud del sonoro idioma". ${ }^{32}$

Toda una declaración de fe hispanoamericanista puesto que se habla de una única raza — resultante del mestizaje—, con un mismo idioma y una misma religión. Y para explicar este largo proceso de unión se recurre a la teoría del Progreso como motor de la Historia, junto con el principio darwinista de la evolución de las sociedades como resultado de la lucha y de la victoria del fuerte sobre el débil: "Hay un foco — Progreso— a do tiende afanoso, casi siempre inconsciente, el humano rebaño, cuyos medios de lucha y avance afirman que el débil sucumba al empuje del fuerte" ${ }^{33} \mathrm{~A}$ modo de demostración, incluyen una larga disgresión sobre la sucesión de imperios y civilizaciones desde el imperio romano hasta la época napoleónica. En este sentido, la raza ibérica es a su vez fruto del mestizaje, de la sangre de los hijos del Lacio, de las selvas nórdicas y de los hijos del Islam. ${ }^{34} \mathrm{Y}$, que esta ley histórica se cumple inexorablemente lo confirma la misma evolución de las culturas prehispánicas mexicanas.

En el capítulo segundo, los dos españoles realizan un rápido recorrido por el pasado mexicano anterior a la llegada de Cortés, insistiendo en los choques continuados que generaron la desaparición de unas culturas y la emergencia de otras. Primero enumeran los distintos pueblos que, en sucesivas oleadas desde el Norte, poblaron el espacio mexicano: los ópatas,

32 Ibídem, pág. 19.

33 Ibídem, pág. 22.

34 Ibídem, pág. 24. 
los pimas, los yaquis, los apaches, los tarahumaras, los huastecas, los totonacos, los tarascos, los mixtecos, los zapotecos, los mijes, los zoques, los chontales y los mayas. Se desprende ya la idea de diversidad y mezcla racial desde el pasado más remoto de México. A continuación, se explica ese pasado prehispánico, citando a las principales culturas. Así, "los otomíes cedieron, resistentes, a la irrupción tolteca que regaron a su paso soberbias construcciones. Pueblo escogido que consigo traía la semilla de una cultura bien definida, con carácter propio y refinada asaz. La cual, los chichimecas, innúmeros y fieros, hubieron de estrujar llegado el tiempo, como luego, en sus redes el pueblo matlazinca los estrujó a su vez. Sobre los unos y los otros, la familia nahoa aportó nuevas luchas...". Así hasta el triunfo azteca. ${ }^{35}$ Dos elementos caracterizan, por consiguiente, el ser mexicano: la mezcla de razas y la sucesión violenta de culturas que se dominan unas a otras. Desde esta perspectiva, la conquista por los españoles se inscribiría en el orden histórico natural de México: una nueva raza, la ibérica, se mezcla a la existente; y este proceso de choque y fusión étnica y cultural es violento, como lo fueron los anteriores, pero profundamente enriquecedor puesto que "sangre azteca e íbera, confundidas, mezcladas, produjeron un tipo humano superior, que, sonada la hora, una patria formó sobre cimientos graníticos a prueba de sacudidas recias". ${ }^{36}$ Tenemos, pues, el origen de la moderna nación mexicana, nación mestiza por definición y en modo alguno nación india — de Moctezuma o de Cuauhtémoc- tal y como lo expresaron los mismos fundadores, los padres de la patria, los héroes de la independencia. ${ }^{37}$ Los dos españoles recogen así la idea de la mexicanidad identificada con el mestizaje, defendida por la denominada corriente mestizófila, representada por figuras de la talla de Francisco Pimentel, Vicente Riva Palacio, Justo Sierra y, ya en el siglo XX, Andrés Molina Enríquez. ${ }^{38}$ La mestizofilia se había ido afianzando a lo largo del

35 Ibídem, págs. 32-33. Por falta de espacio y para no alargar sobremanera este estudio, no es posible analizar en profundidad estas referencias al pasado prehispánico, en las que quedan plasmadas las novedades historiográficas que se fueron sucediendo a lo largo del siglo XIX.

36 Ibídem, pág. 36.

37 “...que pensadores y héroes y caudillos de la gran epopeya de la Independencia y Patria, jamás pensaron —ni pensar podían semejante dislate — en restaurar de Moctezuma el débil o del heroico Cuauhtémoc el solio derrumbado, sino en crear la Nación, que a celebrar se apresta en fecha próxima la primera centuria de su edad como pueblo". Ibídem, pág. 38.

38 Vicente Riva Palacio había otorgado al mestizo la exclusiva de la nacionalidad mexicana ya que es el único que puede sentir a México como su patria al ser el único que puede distinguirse de España y del Anahuac, naciones alejadas de la mexicana respectivamente en virtud del espacio y del tiempo; Basave Benítez, Agustín: México mestizo. Análisis del nacionalismo mexicano en torno a la mestizofilia de Andrés Molina Enríquez, México, 1992, pág. 30. 
siglo XIX y, durante el Porfiriato, se había consolidado al calor de las polémicas relativas a las teorías racistas imperantes en Europa (difusión de las teorías de Darwin, Spencer, Gustave Le Bon, etc.). Por eso, cuando los dos españoles se refieren al tipo humano superior fruto de la raza azteca e ibérica, conectan con la definición dominante de la nacionalidad mexicana.

En este contexto cobra todo su sentido la alocución de Morelos - que pone fin a la primera parte del relato y que constituye el primer acontecimiento excepcional del viaje iniciático. Es, por tanto, uno de los más brillantes personajes de la independencia mexicana quien se dirige a los dos periodistas desde las cimas de la inmortalidad. Y es él el elegido por los españoles para exponer la tesis del abrazo de Cortés y Cuauhtémoc como símbolo de la unidad de los dos componentes fundamentales de la nueva identidad mexicana.

“Todos allí, en fraternal congreso, los rivales de ayer —héroes lo mismo y lo mismo inmortales, pues a todos cobija la redentora y siempre augusta, tres veces santa enseña de POR LA PATRIA pues por ella cayó el estoico príncipe de bronceada tez y alma de acero, y por ella también hubo el conquistador con la fama de hábil capitán y sagaz gobernante la negra abrumadora sentencia de que pesasen por siglos sobre su nombre y sus gestas y memoria montes de vilipendio e ignominia; y aun por ella, del atrio de una iglesia salió camino del luminoso palacio etéreo de los grandes hombres un cura humilde". ${ }^{39}$

Morelos apadrina así el proyecto y sella la definitiva reconciliación entre los dos pueblos, entre un México próspero y una España hermana y no dominadora, una España que tuvo que liberarse también del yugo absolutista y que, por eso mismo, no pudo darles a los pueblos del Nuevo Mundo el único bien que no tenía, la libertad. Se trata de la visión adoptada por los liberales españoles de la segunda mitad del siglo XIX, la de una común empresa liberadora en España y en América, un proceso que se desarrollaría de forma paralela a ambas orillas del Atlántico y de manera igualmente violenta y dolorosa. La lucha por la libertad sería, dentro de esta concepción liberal común a mexicanos y españoles, otro elemento motor de la Historia, estrechamente unido a la noción de Progreso. Tenemos así todos los componentes de la teoría liberal triunfante en el siglo XIX, pues no hay que olvidar que, durante la primera mitad de esa centuria, para los forjadores de la patria mexicana, "nacionalidad y liberalismo fueron una misma cosa". ${ }^{40}$

39 Segarra, J.; Juliá, J.: La ruta..., pág. 55.

40 Reyes Heroles, Jesús: El liberalismo mexicano, México, 1982, t. II, pág. 454. 
En el capítulo quince, se concreta simbólicamente la reconciliación entre España y México, con el abrazo de Cortés y de Cuauhtémoc en la cima del Popocatépetl. ${ }^{41}$ El lenguaje es si cabe más retórico y ampuloso puesto que se trata del gran momento de exaltación nacionalista, en el triple sentido - mexicano, español e hispanoamericano. La aparición de los dos personajes míticos (que surgen respectivamente de un león Castilla - y un águila — el imperio azteca) viene precedida del desfile de insignes personajes de la historia mexicana, todos juntos y mezclados independientemente de la época en que les tocó vivir. La lista, como antes la de los escritores, resulta muy significativa. En efecto, el cortejo de héroes se compone de representantes del mundo azteca, Nezahualcóyotl y Moctezuma entre otros, pero sobre todo de representantes del mundo colonial y del período independentista. Llama la atención la ausencia de personajes femeninos. El pasado es masculino y no hay ninguna mujer en el cortejo de la cima del volcán. La primera gran figura de la historia de México, Malintzin, la Malinche, aparece como encarnación del sentimiento y sobre todo como primera conversa a la nueva fe redentora, pero no se profundiza demasiado en este personaje, que abre viejas heridas al ser considerada una traidora por colaborar activamente en el triunfo de Cortés. Así, los dos periodistas no hablan de ella directamente sino que la citan recurriendo al artificio de la aparición del piloto Antón de Alaminos, el cual se refiere a ella como doña Marina, su nombre cristiano. ${ }^{42}$ Es significativo que se aluda a su carácter de primera conversa americana y no al de madre de mestizos. Puesto que el objetivo de la empresa es reconciliar y no enfrentar, esta relativa ausencia de Malintzin resulta aparentemente lógica, pero habría que rastrear, sin embargo, los juicios de valor relativos a esta singular mujer en los escritos decimonónicos.

De la época colonial, aparecen conquistadores, misioneros y funcionarios reales. Sin embargo, la elección de los nombres revela una intención muy clara: hacer hincapié en la labor civilizadora, en la tarea de construcción de una nueva cultura y no de destrucción de las culturas existentes, en la paz y no en la guerra. De ahí que se citen los nombres de virreyes ilustres que se significaron en la tarea de proteger a los indígenas, fomentar el

41 AI insistir en el carácter mestizo, mediante el recurso insistente a la imagen del abrazo entre Cortés y Cuauhtemoc, los dos periodistas demuestran conocer la relativamente reciente polémica generada en 1894 por Francisco G. Cosmes al otorgar la paternidad de la mexicanidad a Hernán Cortés, desplegando una apasionada hispanofilia y un rabioso antiindigenismo; Basave Benítez, Agustín: México mestizo..., pág. 38.

42 Segarra, J.; Juliá, J.: La ruta..., págs. 87-88. 
desarrollo económico del virreinato y la instrucción, como Antonio de Mendoza, los dos virreyes Velasco, el arzobispo Palafox o el virrey ilustrado Revillagigedo. En cambio no figuran conquistadores exceptuando el gran protagonista, Cortés, y el relator de la gesta cortesiana, Bernal Díaz.

En cuanto a la difusión de la religión católica, la elección de ilustres misioneros como fray Pedro de Gante, Vasco de Quiroga con su utopía de los hospitales-pueblo y fray Martín de Valencia - nombres de la primerísima hora de la conquista evangelizadora - revela una sabia prudencia y el conocimiento de la espinosa situación imperante en México en lo relativo a las relaciones entre la Iglesia y el Estado. Al ensalzar a los héroes del Evangelio, ejemplo de pobreza, dedicación y bondad, se condena implícitamente a la Iglesia como poder que participa en las luchas políticas y que amasa tierras. Por último, en el ámbito cultural, se destaca a Sigüenza y Góngora y a Juan Ruiz de Alarcón, entre otros y, de nuevo, hay que destacar la omisión de figuras femeninas, como Sor Juana Inés de la Cruz, la cual permaneció en el olvido hasta prácticamente la aparición del estudio de Octavio Paz. El México independiente, con excepción de Iturbide, está marcado por el liberalismo ya que todos los citados pertenecen al bando liberal que acabó triunfando tras el largo período de guerras civiles: Hidalgo, Morelos, Bravo, Guerrero, Juárez, Ocampo, Lerdo, Altamirano. Y para insistir en esa visión liberal de la Historia, aparece Prim, símbolo del liberalismo español cuya gloria no se ve empañada por su participación en la Intervención de 1862, sino todo lo contrario puesto que, a los ojos de los españoles, supo retirarse a tiempo, a diferencia de los franceses.

Este artificio literario no supone ninguna originalidad por parte de los dos periodistas ya que durante la celebración del Centenario de la Independencia, Porfirio Díaz presidió un desfile de carácter histórico, en el que aparecieron Cortés y Moctezuma junto con otras relevantes figuras del pasado mexicano. En las dos ocasiones se procede a una selección del pasado para avalar la teoría del Progreso y para presentar a don Porfirio como el directo sucesor de esos héroes, en especial de los protagonistas de la independencia. El Porfiriato busca su legitimidad mediante la identificación de su particular visión del Estado y del desarrollo económico y social - un proyecto liberal en lo económico pero no así en lo político- con la supuesta esencia única de la Nación mexicana y de la "mexicanidad".

En conclusión, de la aventura inicial, individual, de los dos periodistas por tierras exóticas, se pasa a una campaña de propaganda destinada, por una parte, a ensalzar los logros económicos y políticos del régimen 
establecido y, por otra, a reelaborar el pasado con vistas a cimentar la identidad mexicana. En efecto, el abrazo de Cortés y de Cuauhtémoc encierra una honda significación puesto que, para los autores y para el poder porfirista, pone fin al desgarro interior padecido por el nuevo pueblo mexicano surgido del mestizaje racial y cultural. Este desgarro, y la consiguiente angustia, provenían de la búsqueda de una identidad propia, distinta de las dos herencias, española y azteca, en un intento por cerrar la herida abierta por la Conquista. ${ }^{43}$ Esta reconciliación — por obra de la política de Orden y Progreso - sería la reconciliación del pueblo mexicano consigo mismo, con sus raíces, y supondría su plena madurez como pueblo. Sin embargo, como es sabido, la Revolución que estalló en 1911 intentó redefinir la mexicanidad partiendo de otros presupuestos, demostrando que la herida seguía abierta y que el intento porfiriano había fracasado en parte.

43 Demuestran gran prudencia al exaltar la figura de Cortés pero dentro de los parámetros "mestizos" imperantes en México, combinando así hispanoamericanismo, españolismo y mexicanismo. En este sentido, la obra de los dos valencianos es un producto propagandístico perfecto y completo, ya que no se limita a exaltar los logros políticos y económicos del Porfiriato, sino que divulga, a ambas orillas del oceáno, las teorías dominantes sobre la nacionalidad y la mexicanidad, consiguiendo contentar tanto a mexicanos como a españoles. 